\title{
The Black-footed Ferret
}

\section{Tim W. Clark}

The black-footed ferret depends on prairie dogs for both shelter and food, living in their underground 'towns' and preying on them. But the prairie dogs, regarded as pests by the ranchers and farmers, have been subjected to intensive poisoning campaigns which successfully exterminated them over most of their range and heavily reduced their numbers in the rest. This has brought the ferrets to the verge of extinction. A conservation management programme is urgently needed but difficult to devise, because so little is known about these elusive, nocturnal and now very rare underground dwellers. The author believes that computer simulation models now offer a good study method, and suggests how this should be done.

In Sioux it is Pispiza etopta sapa, 'black-faced prairie dog'; to science, Mustela nigripes, the black-footed ferret, one of North America's rarest and most endangered mammals. The Indian name indicates the most significant fact known about this ferret, that it is almost totally dependent on prairie dogs. And as prairie dogs are poisoned in the name of efficient range management the ferret is being condemned to extinction.

The ferret's rarity makes it difficult to observe; the fact that it is nocturnal, and may be active above ground for only a few minutes every few days, makes observation nearly impossible, and large gaps still exist in our knowledge of its biology. A viable management plan depends on knowing more, and the biologist must turn detective. Time is rapidly running out for the ferret.

There are a number of indirect ways of studying ferret biology - in fossils (palaeontology), in Indian museums and ethnographies (anthropology), through Siberian ferrets (comparative evolutionary biology), and by complex computer simulation models (computer sciences and mathematical biology).. A synthesis of these approaches may yield some insight into the relation of the black-footed ferret to its environment.

Since 1851 when Audubon and Bachman obtained the first specimen known to science, approximately 1000 black-footed ferrets have been re-

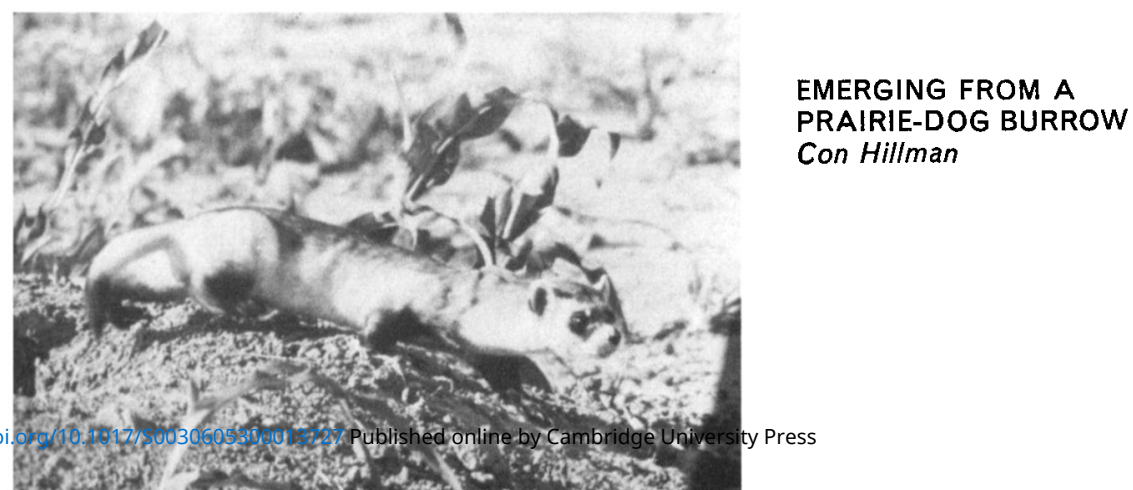

EMERGING FROM A PRAIRIE-DOG BURROW Con Hillman 
ported, nearly all brief sight observations; only about 100 specimens exist in museums. All reports show that ferrets were once distributed from North Dakota to Texas, and from Nebraska to Utah, the same area as that occupied by prairie dogs. Half the sightings since 1899 come from South Dakota; Wyoming and Montana account for a quarter. Between 50-100 reports come from each of Nebraska, Kansas, Oklahoma, Texas, New Mexico, and Colorado; North Dakota records only 25 reports and Utah only two. These figures could, of course, be misleading in that equal efforts may not have been made in all states. A few unverified reports come in each year.

Western South Dakota, where in 1964 the ferrets were 'rediscovered', is the only place where they can be consistently located every year. From 1964 to 1972 only 64 were seen, 38 young in 11 litters and 26 adults on 17 different prairie dog towns in the area. In 1973 only three were observed, in 1974 only two, and in 1975 (up to October) none; but researchers in South Dakota believe that the prairie dog population size and town density there 'appears to be maintaining a ferret population'.

\section{Origins}

Black-footed ferrets originated in the Old World and reached North America via the Bering land bridge during the last ice age (Pleistocene). The oldest fossil remains come from Fairbanks District, Alaska, and date from about 32,000 years ago. Twelve other Pleistocene and post-Pleistocene ferret records are known; six of these fall outside the current range (the 1000 recent records). In general, the older fossil records show a more western and northern distribution to Idaho, Alberta, and up to central Alaska. At six of the 13 fossil sites there were also prairie dogs. They are probably of Pleistocene origin, their ancestors having migrated to North America by the same route as the ferrets. At that time central Alaska was a grassland environment with potential habitat for the dispersing prairie dogs and ferrets.

Several fossil sites were also occupied by Indians. Ferret remains were found at Jaguar Cave in Idaho - 11,580 250 B.P. (Before the Present) - and in Little Box Elder Cave in Wyoming, where 15 ferrets and at least 73 prairie dogs were discovered. Other sites with fossil ferrets are Moonshiner Cave in Idaho, Ore Cave in Montana, and Isletta and Burnett Caves in New Mexico.

More recently, five Indian groups - Sioux, Blackfeet, Crow, Cheyenne, and Pawnee - have used ferrets in a variety of ways, from food to religious rites. Blackfeet in Montana used ferret as well as ermine weasel hides as pendants on their chiefs' headdresses. Crow Indians of Wyoming and Montana used ferrets in their sacred tobacco society; at the turn of the last century about 30 chapters apparently existed in connection with the tobacco cultivation, each of which claimed an associated animal - weasel, otter, bison, etc. The properties ascribed to these animals and their significance are unknown. It is impossible to determine how abundant ferrets were, but their use by Indian tribes shows both their widespread distribution and their association with prairie dogs, suggesting that they were commoner than now.

Since ferrets depend on prairie dogs for food and shelter, an estimate of past numbers of prairie dogs might shed some light on the history of ferrets. Prairie dogs have been abundant since recorded history. They are mentioned in the journals of Coronado (1541), François and Louis Verendrye (1742), 
Black-footed ferrets photographed in South Dakota, the only state where they can certainly be seen every year, by Luther $C$. Goldman

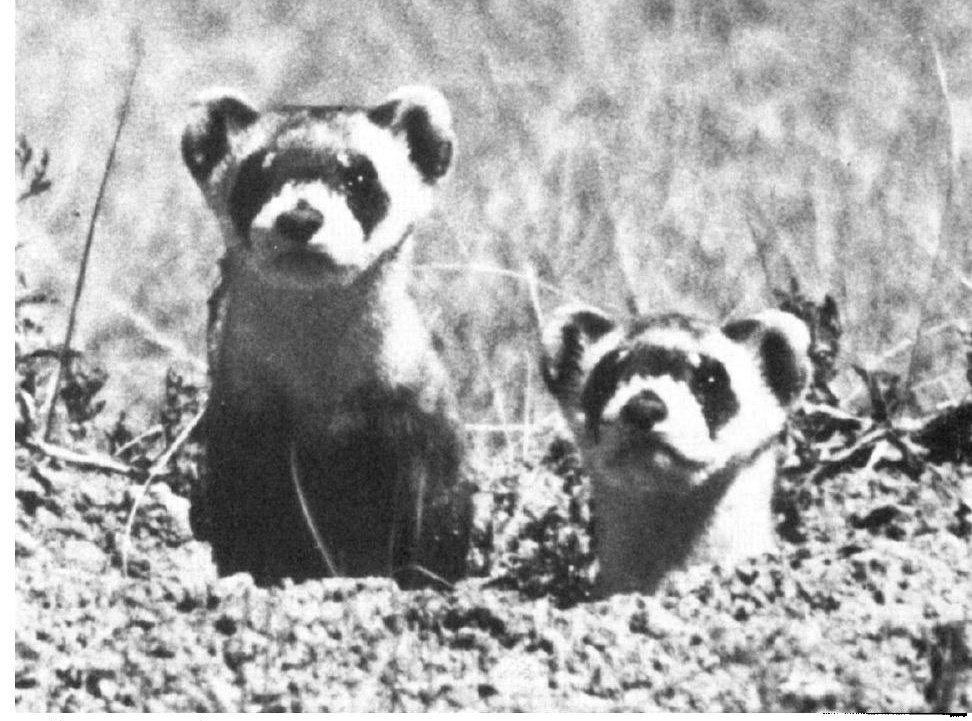

Zeb Pike (1806-7) and many others. Lewis and Clark (1804) reported that 'this animal appears here in infinite numbers'. The historian Francis Parkman (1864), describing his journey across the northern Great Plains, tells how 'the prairies teemed with life'. Toward the end of the last century, just before the start of the massive prairie dog poisoning campaigns, the famous naturalist, E. T. Seton, estimated that there were 5000 million prairie dogs in North America. We can only guess that ferrets also maintained a healthy population in this vast sea of grass and prairie dogs.

One of the richest sources of indirect information about the ferret is a comparison with its closest living relative - the Amur Siberian polecat Mustela eversmanni amurensis. The fossil ferret from Alaska more closely resembles living Siberian ferrets than it does the American black-footed ferret. The American ferret probably became isolated and specialised as it adapted to the Great Plains and intermontane regions of the Rocky Mountains of North America.

The Siberian and American ferrets show a core of behavioural and ecological similarities in habitat, predatory behaviour, activity patterns, burrows and shelter, home ranges and movements, and population dynamics. But they differ in several important aspects - the Siberian ferret; for example, produces an average of nine young (range 4-18), while the American produces only four (range 3-5). Many such differences can be explained by differences in the temporal and spatial productivity of their environments. In Siberia, with the wide range of climate, the ferret's environment is characterised by large changes in vegetation productivity. Their habitat is spatially patchy, with peak productivity every summer in the form of relatively discrete, isolated ground-squirrel (suslik) colonies, their chief prey. In summer food and shelter are virtually unlimited, but in the autumn, when the susliks begin to hibernate, productivity drops off sharply and the ferrets are forced to disperse and find other prey; home ranges become greatly enlarged and they may have to go far in search for food. That winter mortality is high is suggested by the large litter size (averages $=8-9$, range $4-18$ ). In very severe weather the ferrets 
retreat below ground, in an inactive state, for several days at a time. Factors such as flooding, fires, etc., tend to limit population sizes.

The American ferret lives in association with two types of prairie dogs, and the differences between them may greatly influence the ferret's survival strategies. In South Dakota, where they associate with black-tailed prairie dogs Cynomys ludovicianus, the seasonal changes in availability of prey are relatively small, because this prairie dog does not hibernate but only becomes inactive below ground for a few days during severe weather. But ferrets that live in association with white-tailed prairie dogs C. leucurus, as in western Colorado, Utah, Wyoming, or Montana, find, like the Siberian ferret, marked seasonal fluctuations in their prairie-dog prey, for this species hibernates for up to four months each year, forcing the ferrets to find other prey. Recent evidence from western Wyoming shows that nearly all ferret sighting on white-tailed colonies are adjacent to relatively extensive meadows along stream courses, where there are relatively large populations of other rodents; voles and mice such as Microtus, Mus, Peromyscus - the species used by the Siberian ferret each winter - and the American ferret in less productive areas probably also turns to these prey in winter.

The higher rainfall of the central Great Plains, the range of the black-tailed prairie dog, creates a more productive environment than that of the drier western areas, home of the white-tailed. This allows the black-tailed to live in higher densities and remain active all year. This in turn allows them to maintain the already rich habitat at the more productive vegetation stages, which again foster even larger colonies. Black-tailed colonies may reach thousands of individuals covering extensive areas, while the white-tailed seldom exceed 100 animals in a colony of a few hectares in area. Consequently the blackfooted ferret has become more specialised on black-tailed prairie-dog colonies.

One specialisation is its nocturnal habit in response to prey size. The availability of year-round food and shelter has resulted in the small litter size (averages $=4 \cdot 0$, range 3 to 5 ) and minimum winter mortality. Factors such as aggression between ferrets may affect survival, but in recent years the chief mortality causes may have been poisons (e.g. 1080), human-introduced diseases (e.g. dog distemper), and loss of habitat (i.e. poisoning of prairie dogs).

One proposal for saving the black-footed ferret is to create reserves of suitable size and habitat quality. The first question is how much land will be enough and what exactly characterises a high-quality habitat. How many ferrets can be supported on 1000 acres, or 10,000 acres, or 100,000 acres? How many prairie dog towns of what size are needed to support even one ferret? Little is known of the effects of the ferrets on prairie dog populations. Some researchers have suggested that ferrets may be capable of exterminating nearly all prairie dogs in a town; other indicate that, although the size of a prairie-dog town may be influenced by a ferret, numbers are not greatly reduced.

The immense difficulty of conducting long-term studies on this particular predator-prey interaction means we must turn to the next best approach computer simulation models. This is a powerful new tool in ecology that can give tremendous insights into complex interactions like this.

First, we have to define the limits of our computer model. For instance we may want it to describe the complex interactions of a ferret on a single black- 
tailed prairie-dog town of, say, 3000 acres. In turn we could model how many ferrets could be supported by such a prairie dog concentration. Our theoretically derived figure of potential ferret-population size can be compared with the numbers of ferrets that have actually been seen, and we can suggest that we are observing only a given percentage of the potential total or modify the model.

By viewing this predator-prey system as a network of simple energy flows with feedback loops, we can break the system down into a series of relationships between important variables and explicitly define flows between them, and the resulting model can be programmed into a computer. The computer will play the roles of all variables simultaneously and simulate the behaviour of the real system. Experimenting with the simulation model may yield much insight into the controlling forces of a natural system.

Numerous complex variables interact to produce the observed results, and the key to a useful simulation model, or for that matter any analysis of nature, is an accurate definition and representation of the important variables and their relationships in the system (feedbacks). The diagram here shows how

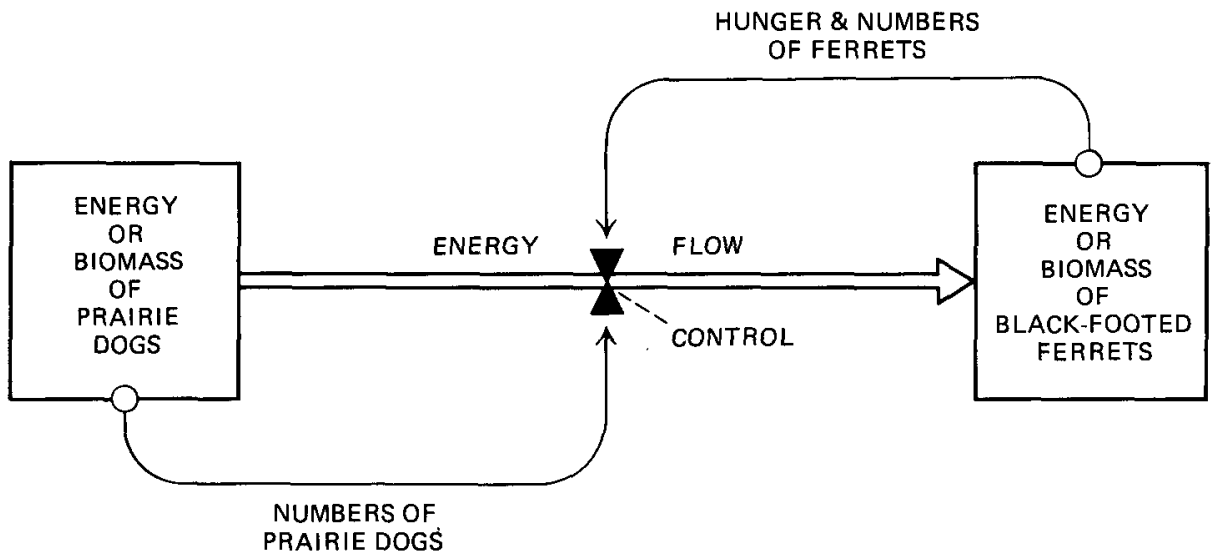

an extremely simplified flow (ferret feeding behaviour) with two feedback mechanisms can be represented. Both the two feedback systems shown here (arrows with open circles) can control the number of prairie dogs consumed.

Since computer models are only as good as the available data on which they are based, there are immediately limitations on what any ferret computermodel can do. If we want to quantify all the relationships we run into problems, since only limited data exist on some critical aspects of ferret lifehistory. This is where data on the Siberian ferret are especially valuable, for the close similarity of the two species permits the Siberian data to be used in computer models of American ferrets.

In our case we want to know such things as the effects of a ferret, of given weight and food requirements, on a prairie dog population. An adult male may have a different effect from a pregnant female. Since prairie-dog population age and size structure changes over the year it is important to have good descriptions of seasonal changes in these parameters, and fortunately we have this data. A computer model such as this is now under construction and, it is 
hoped, will provide us with insights into ferret biology. At the least the effort will pinpoint the weaknesses in the existing ferret data.

South Dakota researchers recently concluded that 'because the ferret is chiefly dependent upon prairie dogs for shelter and diet, management in favour of prairie dog populations is management in favour of ferret populations'. However, prairie dog populations today are only a very small fraction of their former numbers, thanks to the success of the poisoning campaigns. North Dakota, which formerly had 'hundreds of thousands' of prairie-dog towns, has only about 50 'small' ones left. South Dakota had about 1,756,720 acres of prairie dogs in 1923; in 1968, it was estimated, only 45,000 or 2.6 per cent remained. A 98.6 per cent reduction in prairie dog acreage has occurred in Kansas since 1905, when an estimate showed 2,500,000 acres occupied by prairie dogs; only 35,000 acres are left. Oklahoma has only 15,000 acres left, and estimates on prairie dogs in Texas show a reduction of 99.6 per cent since the 1890 s.

Several proposals for managing the ferrets have been suggested. They include: 1, exploring all feasible means of retaining adequate numbers of prairie dogs and ferrets on both public and private lands; 2 , experimenting with transplanting and releasing ferrets into areas where prairie dogs are protected; and 3, developing materials for prairie-dog and other animal control that will not poison ferrets.

The future of the rare black-footed ferret is uncertain. Extinctions are not new. What is new is the vastly accelerated rate of extinctions caused by human activities. Today 10-12 per cent of the world's mammals can be considered endangered. In the USA the situation is worse-perhaps 130 of the 400 mammals are believed to be threatened with extinction. The ultimate protection of nature, its ecological systems, and endangered forms of life, demands a plan, of which the core is a management of the wilderness and an enlightened use of wild resources based on scientific research and measurement.

Dr Clark is at the University of Wisconsin, Madison, USA. In a later issue of Oryx we hope to publish an article by him on the prairie dogs.

The photograph on page 277 is by Luther C. Goldman, Fish and Wildlife Service.

\section{The Butterfly Smugglers}

Angus Hutton, FPS Consultant in Papua New Guinea, writes:

I have been in the south-east islands, a paradise and totally 'underdeveloped', setting up butterfly farms. Unfortunately, butterfly exploiters have been in there over the years and taken every pupa they could lay hands on for 20 cents a specimen. The effect on a small population of endemic fauna has been disastrous, but it is not too late to save the situation. The expatriate exploiters involved have been prosecuted and convicted for possessing protected fauna; one was deported and further cases are pending. Specimens of Ornithoptera celestes collected 3-4 years ago are now on sale in England for $£ 36$ a pair. Thanks to the assistance of FPS and other folk in England and an Australian Customs \& Excise official, we now have a full list of our smugglers, with details of routes used, couriers' names (and aliases) and retail outlets in the UK, Europe, USA and Japan and the gate has been firmly shut (we hope). Our whole wildlife laws are being tightened up and penalties have been drastically increased. 